\title{
BMJ
}

\section{Statin treatment for primary prevention of vascular disease: whom to treat? Cost-effectiveness analysis}

\author{
JP Greving, research fellow in clinical epidemiology, ${ }^{1} \mathrm{FL}$ V Visseren, internist and professor of vascular \\ medicine, ${ }^{2} \mathrm{GA}$ de Wit, associate professor of health technology assessment, ${ }^{1,3} \mathrm{~A}$ Algra, professor of clinical \\ epidemiology $y^{1,4}$
}

Julius Center for Health Sciences and Primary Care, University Medical Center Utrecht, 3584 CX Utrecht, Netherlands

${ }^{2}$ Department of Vascular Medicine, University Medical Center Utrecht

${ }^{3}$ Center for Prevention and Health Services Research, National Institute of Public Health and the Environment, Bilthoven, Netherlands

${ }^{4}$ Utrecht Stroke Center Department of Neurology and Neurosurgery, Rudolf Magnus Institute of Neuroscience, University Medical Center Utrecht Correspondence to: J P Greving J.P.Greving@umcutrecht.nl

Cite this as: $B M J$ 2011;342:d1672 doi:10.1136/bmi.d1672

\section{ABSTRACT}

Objective To assess the cost-effectiveness of low dose statins for primary prevention of vascular disease, incorporating current prices, non-adherence (reduced clinical efficacy while maintaining healthcare costs), and the results of the recently published JUPITER trial.

Design Cost-effectiveness analysis using a Markov model. Sensitivity analyses and Monte Carlo simulation evaluated the robustness of the results.

Setting Primary care in The Netherlands.

Participants Hypothetical populations of men and women aged 45 to 75 years without a history of vascular disease at different levels of risk for vascular disease (myocardial infarction and stroke) over 10 years.

Interventions Low dose statin treatment daily versus no treatment for 10 years.

Main outcome measures Number of fatal and nonfatal vascular events prevented, quality-adjusted life-years (QALYs), costs, and incremental cost-effectiveness ratios over 10 years.

Results Over a 10-year period, statin treatment cost $€ 35000$ ( $£ 30000, \$ 49000$ ) per QALY gained for men aged 55 years with a 10 -year vascular risk of $10 \%$. The incremental cost-effectiveness ratio improved as risk for vascular disease increased. The cost per QALY ranged from approximately $€ 5000$ to $€ 125000$ when the 10 -year vascular risk for men aged 55 years was varied from $25 \%$ to $5 \%$. The incremental cost-effectiveness ratio slightly decreased with age after the level of vascular risk was specified. Results were sensitive to the costs of statin treatment, statin effectiveness, non-adherence, disutility of taking medication daily, and the time horizon of the model.

Conclusions In daily practice, statin treatment seemed not to be cost-effective for primary prevention in populations at low risk of vascular disease, despite low costs of generic drug pills. Adherence to statin treatment needs to be improved to enhance the cost-effectiveness of the use of statins for primary prevention.

\section{INTRODUCTION}

Cardiovascular disease is the leading cause of death and disability in more developed countries and contributes substantially to healthcare spending. ${ }^{12}$ Several clinical trials and meta-analyses have shown the beneficial effects of statins in reducing mortality and cardiovascular morbidity in a range of different populations and risk groups. ${ }^{34}$ Four recent systematic reviews focused on the efficacy of statins in primary prevention populations at high risk, and concluded that statin treatment was associated with a significant reduction in the risk of major vascular events, but it had no benefit on all cause mortality. ${ }^{5-8}$

In view of the large treatment effects on major vascular events, a considerable number of people in high risk primary prevention populations could probably benefit from long term statin use. Recently, the introduction of generic statins has led to sharp price reductions. Consequently, statin use today could come at a reasonable price in lower risk primary prevention populations. However, a substantial gap exists between expected and actual benefits, which can be attributed to poor adherence to statin therapy. ${ }^{910}$ Furthermore, treating all people in high risk, low risk, and very low risk primary prevention populations would mean treating a very large number of people and could have important implications for public health costs and use of healthcare resources. Moreover, healthy people might not wish to receive medical therapy, and such considerations should be taken into account when deciding on the use of statins. ${ }^{11}$ Decision analysis is an appropriate way to gain insight in the balance of benefits, risks, and costs of statin treatment in different subgroups. ${ }^{12}$

To help inform clinical and policy decisions about primary prevention of vascular disease, we did a costeffectiveness analysis that examined the use of statins in men and women of different ages with various underlying levels of vascular disease risk. This analysis extends the results of previous cost-effectiveness analyses ${ }^{13-18}$ by examining the effect of non-adherence, examining a greater number of subgroups, and including generic statin prices and updated estimates of statin effectiveness. This analysis incorporates the results from the recently published JUPITER trial (Justification for the Use of Statins in Prevention: an 
Intervention Trial Evaluating Rosuvastatin), which is probably the last large placebo controlled primary prevention trial with statins. ${ }^{19}$

\section{METHODS}

\section{Model structure}

A Markov model was used to evaluate the costs and effects associated with low dose statin treatment and no treatment. ${ }^{20}$ The model was designed to simulate cohorts of apparently healthy men or women aged $45,55,65$, or 75 years with various levels of risk of vascular disease (myocardial infarction and stroke) within 10 years (10-year vascular risk). The model comprises six health states: healthy, post-myocardial infarction, post-major stroke, post-minor stroke, postmyopathy, and death (figure 1). All people entered the model in the healthy state. From there, age and sex specific probabilities of fatal and nonfatal myocardial infarction, fatal and nonfatal stroke, or dying of another cause determined which people made transitions to other health states, in each annual cycle. People who experienced adverse effects from statin therapy (myopathy and rhabdomyolysis) stopped taking their statins permanently; thereafter their procession through the model was similar to that of healthy people who did not use statins. We did not consider angina pectoris or transient ischaemic attacks as separate health states in our model because insufficient data about the effects of statins on these outcomes were available. Additionally, these outcomes are transient health states that may be considered an integral part of survival with vascular disease without specific long term consequences.

\section{Model variables}

Probabilities of transition to the next health state, effectiveness of statin treatment, utilities, and costs for a 55 year old person are shown in table 1 . Webtable 1 shows these data for people aged 45,65 , and 75 years old. Annual baseline incidence rates of initial vascular

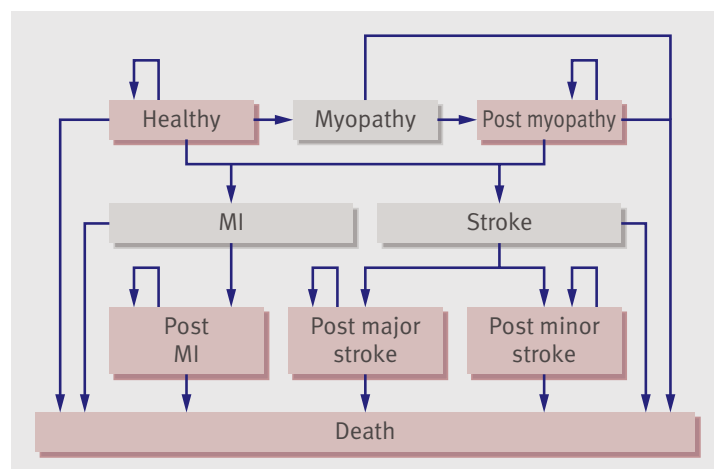

Fig 1 | General structure of the Markov model. People enter the model while taking statins or not and can progress from healthy to one of the other health states (shaded boxes), including death, in each cycle. Those who have statin related adverse effects (myopathy and rhabdomyolysis) stop taking statins. $M \mathrm{I}=$ myocardial infarction events (fatal and nonfatal myocardial infarction and stroke) by age group and sex were obtained from a record linkage study of nationwide registers and included hospitalised patients of all ages and deaths out of hospital. ${ }^{12122}$ We calculated age specific incidence rates with linear interpolation between age groups. We used these rates in our model rather than fixed annual rates, because incidence rates increase with age. Similarly, we derived age and sex specific case fatality rates for myocardial infarction and stroke. ${ }^{223}$ The risks of adverse effects associated with statins (myopathy and rhabdomyolysis) were drawn from a systematic review of cohort studies supported by data from randomised controlled trials. ${ }^{24}$ The case fatality of rhabdomyolysis was estimated at $10 \% .{ }^{24} \mathrm{We}$ derived age and sex specific annual probabilities of dying from Dutch life tables. ${ }^{25}$ These data were used to take into account the ageing of the cohort in the model.

Because we were interested in primary prevention, we did not simulate or examine the details of a patient's course after a first, nonfatal vascular event. Instead, we assigned survivors of a first vascular event an increased risk of death based on the average long term experience (for example, increased event rate) of patients after a first vascular event. ${ }^{26-29} \mathrm{We}$ assumed that all patients received optimal secondary prevention and we applied a two-fold increased risk for death to the general mortality rates from the Dutch life tables to generate the estimated post event mortality rates. We assumed that risk of permanent severe disability after stroke is $33 \%$. $^{30}$

\section{Treatment efficacy}

Treatment efficacy was modelled by application of risk ratios from a recent meta-analysis of ten randomised controlled trials of statins for primary prevention to the incidence rates of myocardial infarction and stroke. ${ }^{7}$ We assumed similar treatment efficacy in men and women at different ages since risk ratios did not differ significantly between the sexes, and between elderly and young people, but we varied these estimates widely in the sensitivity analysis to reflect data that suggested that statins have lower relative risk reductions at older ages. ${ }^{7}$ For the base case analysis, we assumed a real world non-adherence scenario. We derived real world adherence rates from the literature $(60 \%$ adherence after year $1,45 \%$ after year $2,40 \%$ after year 3 , and thereafter remaining stable). ${ }^{31-33} \mathrm{On}$ the basis of statin trial data that indicated that adherence to statin therapy was $90 \%$ after one year, $85 \%$ after two years, and $80 \%$ after three years of trial follow-up (i.e. a 'full' adherence scenario), ${ }^{7}$ we calculated reduced adherence rates of 33\% (1-0.6/0.9) in year 1 , $21 \%(1-0.45 /[0.85 / 0.90 * 0.60])$ in year 2 and $6 \%(1-$ $\left.0.40 /\left[0.80 / 0.85^{*} 0.45\right]\right)$ in year 3 . Real world nonadherence was modelled by decreasing statin efficacy and statin pill costs, but leaving the costs of doctors' visits at 50\% and laboratory test monitoring at 100\%. 
Table 1| Incidence, case fatality, and overall mortality rates for a person aged 55 years and effectiveness of statin treatment, utilities, and costs ( $95 \% \mathrm{Cl}$ )

\begin{tabular}{|c|c|c|c|c|c|}
\hline Parameters & Men & Women & Distribution & Data source & Reference \\
\hline \multicolumn{6}{|l|}{ Incidence (per 100000 person-years)* } \\
\hline Myocardial infarction & $426(413$ to 440$)$ & 101 (95 to 108$)$ & Beta & Cohort study & 21 \\
\hline Stroke & 189 (177 to 202) & $116(106$ to 126$)$ & Beta & Cohort study & 1,22 \\
\hline Myopathy & 12 (1 to 33$)$ & 12 (1 to 33$)$ & Beta & Meta-analysis & 24 \\
\hline Rhabdomyolysis & $3.4(1.6$ to 6.0$)$ & $3.4(1.6$ to 6.0$)$ & Beta & Meta-analysis & 24 \\
\hline \multicolumn{6}{|l|}{ One-year case fatality rate* } \\
\hline Myocardial infarction & 0.28 (0.26 to 0.29$)$ & 0.27 (0.25 to 0.30$)$ & Beta & Cohort study & 23 \\
\hline Stroke & $0.18(0.16$ to 0.21$)$ & $0.18(0.14$ to 0.21$)$ & Beta & Cohort study & 22 \\
\hline Rhabdomyolysis & 0.10 (0.08 to 0.12$)$ & $0.10(0.08$ to 0.12$)$ & Beta & Cohort study & 24 \\
\hline Overall one-year mortality rate* (per 100000 person-years) & 658 (607 to 709$)$ & 407 (366 to 448) & - & Actual rates & 25 \\
\hline \multicolumn{6}{|l|}{ Treatment effectiveness of statins (risk ratios) } \\
\hline Major coronary events & $0.71(0.61$ to 0.82$)$ & 0.71 (0.61 to 0.82$)$ & Lognormal & Meta-analysis & 7 \\
\hline Stroke & 0.81 (0.71 to 0.93$)$ & 0.81 (0.71 to 0.93$)$ & Lognormal & Meta-analysis & 7 \\
\hline Real-world adherence, first year & $0.60(0.50$ to 0.70$)$ & $0.60(0.50$ to 0.70$)$ & Beta & Cohort study & $31-33$ \\
\hline \multicolumn{6}{|l|}{ Utilities } \\
\hline Post-myocardial infarction & 0.88 (0.8 to 0.95$)$ & $0.88(0.8$ to 0.95$)$ & Triangular & Interview & 34 \\
\hline Post-major stroke & $0.5(0$ to 0.75$)$ & 0.5 (0 to 0.75$)$ & Triangular & Review & 35 \\
\hline Post-minor stroke & 0.75 (0.63 to 0.90$)$ & 0.75 (0.63 to 0.90$)$ & Triangular & Review & 35 \\
\hline Act of taking statin medication & $0.999(0.995$ to 1.0$)$ & $0.999(0.995$ to 1.0$)$ & Beta & Estimate & $17,36,37$ \\
\hline \multicolumn{6}{|l|}{ Annual cost data $(€)$} \\
\hline \multicolumn{6}{|l|}{ Statin treatment } \\
\hline Simvastatin 40 mg (generic) & $9(4$ to 15$)$ & $9(4$ to 15$)$ & Gamma & Official tariff & 38 \\
\hline Doctors' visit costs & 99 (64 to 142$)$ & 99 (64 to 142$)$ & Gamma & Official tariff & 39 \\
\hline Pharmacists' fee & 25 (10 to 49$)$ & 25 (10 to 49$)$ & Gamma & Official tariff & 39 \\
\hline Laboratory costs & 24 (16 to 35$)$ & 24 (16 to 35$)$ & Gamma & Official tariff & 39 \\
\hline \multicolumn{6}{|l|}{ Post-myocardial infarction } \\
\hline During first year & $17342(17087$ to 17603$)$ & $17342(17087$ to 17603$)$ & Gamma & Cost study & 38 \\
\hline During subsequent years & 1054 (992 to 1118) & 1054 (992 to 1118) & Gamma & Cost study & 39 \\
\hline \multicolumn{6}{|l|}{ Post-major stroke } \\
\hline During first year & 36173 (35801 to 36546$)$ & 36173 (35 801 to 36546$)$ & Gamma & Cost study & 40 \\
\hline During subsequent years & $21122(20839$ to 21408$)$ & 21122 (20 839 to 21408$)$ & Gamma & Cost study & 40 \\
\hline \multicolumn{6}{|l|}{ Post-minor stroke } \\
\hline During first year & $6343(6187$ to 6500$)$ & 6343 (6187 to 6500$)$ & Gamma & Cost study & 40 \\
\hline During subsequent years & 1085 (1021 to 1150$)$ & 1085 (1021 to 1150$)$ & Gamma & Cost study & 40 \\
\hline Death & 2698 (2597 to 2801$)$ & 2698 (2597 to 2801$)$ & Gamma & Expert opinion & 40 \\
\hline
\end{tabular}

*Risk of events and mortality rates increase with advancing age, except for rhabdomyolysis.

\section{Health outcomes}

We determined the expected number of each of the vascular disease events (myocardial infarction and stroke) along with differences in quality-adjusted lifeyears (QALYs). QALYs were calculated by multiplying the time a person remained in a certain health state by the utility associated with that particular health state and subsequent summing up over all health states. Utility weights for the health states after myocardial infarction $(0.88)$, major stroke $(0.5)$, and minor stroke $(0.75)$ were derived from data published in the literature. ${ }^{3435}$ Most studies used time trade-off techniques to generate utility weights. We included a small disutility from taking a statin pill every day $(0.001)$ in the model. ${ }^{17} 3637$

\section{Costs}

We conducted our economic analysis from the perspective of the healthcare payer. Costs of treatment were divided into those incurred by the drug, laboratory tests, doctors' visits, and pharmacists' fees. For our base case scenario, we estimated the annual costs of statin pills at $€ 9$ euros $(£ 7.65, \$ 12.60$; conversion rate $€ 1=£ 0.85, \$ 1.40)$ for $40 \mathrm{mg}$ generic simvastatin. ${ }^{38}$ Since statin pill costs vary greatly between countries (see webtable 2), we varied the drug costs over wide ranges in scenario analyses. Annual costs of laboratory tests were estimated at $€ 24$, cost of doctors' visits at $€ 99$, and of pharmacists' prescription fees at $€ 25$ based on four visits a year. ${ }^{39}$

Costs associated with morbidity after vascular events were divided into costs for the first year and annual costs for subsequent years. Morbidity associated estimates of cost were derived from Dutch costs studies, and if these data were not available, we applied European costs estimates. ${ }^{40-42}$ The associated costs of managing adverse events were expected to be 
Table 2|Men: quality-adjusted life expectancy and costs of statins compared with no statins on cohorts of Dutch men at different ages over a 10 -year period

\begin{tabular}{|c|c|c|c|c|c|c|c|c|c|c|}
\hline \multirow[b]{2}{*}{$\begin{array}{c}\text { Age } \\
\text { (years) }\end{array}$} & \multicolumn{3}{|c|}{ 10-year vascular risk* } & \multicolumn{3}{|c|}{ QALYs } & \multicolumn{3}{|c|}{ Costs $(€)$} & \multirow[b]{2}{*}{$\begin{array}{c}\text { ICER } \\
\text { (€ per QALY) }\end{array}$} \\
\hline & No statins & Statins & $\begin{array}{l}\text { Absolute } \\
\text { risk } \\
\text { reduction }\end{array}$ & Statins & No statins & $\begin{array}{c}\text { Incremental } \\
\text { QALYs }\end{array}$ & Statins & No statins & $\begin{array}{l}\text { Incremental } \\
\text { costs }(€)\end{array}$ & \\
\hline \multicolumn{11}{|c|}{45} \\
\hline & $1.0 \%$ & $0.9 \%$ & $0.1 \%$ & 9.162 & 9.166 & -0.005 & 1192 & 236 & 956 & NA \\
\hline & $2.5 \%$ & $2.1 \%$ & $0.4 \%$ & 9.143 & 9.144 & -0.001 & 1409 & 494 & 916 & NA \\
\hline & $5.0 \%$ & $4.3 \%$ & $0.7 \%$ & 9.111 & 9.107 & 0.004 & 1774 & 925 & 848 & 195372 \\
\hline & $7.5 \%$ & $6.5 \%$ & $1.0 \%$ & 9.079 & 9.069 & 0.010 & 2141 & 1360 & 781 & 78136 \\
\hline & $10.0 \%$ & $8.6 \%$ & $1.4 \%$ & 9.047 & 9.032 & 0.016 & 2511 & 1796 & 715 & 45669 \\
\hline & $15.0 \%$ & $13.0 \%$ & $2.0 \%$ & 8.981 & 8.954 & 0.027 & 3262 & 2678 & 584 & 21651 \\
\hline \multicolumn{11}{|l|}{55} \\
\hline & $2.5 \%$ & $2.1 \%$ & $0.4 \%$ & 8.937 & 8.938 & 0.000 & 1501 & 603 & 898 & NA \\
\hline & $5.0 \%$ & $4.3 \%$ & $0.7 \%$ & 8.900 & 8.893 & 0.007 & 1856 & 1024 & 832 & 125544 \\
\hline & $7.5 \%$ & $6.5 \%$ & $1.0 \%$ & 8.862 & 8.849 & 0.013 & 2215 & 1448 & 767 & 57442 \\
\hline & $10.0 \%$ & $8.6 \%$ & $1.4 \%$ & 8.824 & 8.804 & 0.020 & 2577 & 1875 & 702 & 34995 \\
\hline & $15.0 \%$ & $13.0 \%$ & $2.0 \%$ & 8.746 & 8.712 & 0.033 & 3311 & 2737 & 574 & 17158 \\
\hline & $20.0 \%$ & $17.4 \%$ & $2.6 \%$ & 8.666 & 8.619 & 0.047 & 4059 & 3611 & 448 & 9572 \\
\hline & $25.0 \%$ & $21.8 \%$ & $3.2 \%$ & 8.584 & 8.523 & 0.060 & 4823 & 4499 & 324 & 5395 \\
\hline \multicolumn{11}{|l|}{65} \\
\hline & $5.0 \%$ & $4.3 \%$ & $0.7 \%$ & 8.277 & 8.266 & 0.010 & 2052 & 1265 & 787 & 75237 \\
\hline & $7.5 \%$ & $6.5 \%$ & $1.0 \%$ & 8.228 & 8.210 & 0.019 & 2374 & 1644 & 729 & 38613 \\
\hline & $10.0 \%$ & $8.7 \%$ & $1.3 \%$ & 8.180 & 8.152 & 0.027 & 2698 & 2026 & 672 & 24607 \\
\hline & $15.0 \%$ & $13.0 \%$ & $2.0 \%$ & 8.080 & 8.036 & 0.044 & 3357 & 2799 & 558 & 12652 \\
\hline & $20.0 \%$ & $17.5 \%$ & $2.5 \%$ & 7.978 & 7.917 & 0.061 & 4030 & 3585 & 445 & 7323 \\
\hline & $25.0 \%$ & $21.9 \%$ & $3.1 \%$ & 7.873 & 7.795 & 0.077 & 4719 & 4384 & 334 & 4319 \\
\hline \multicolumn{11}{|l|}{75} \\
\hline & $5.0 \%$ & $4.3 \%$ & $0.7 \%$ & 6.928 & 6.912 & 0.016 & 2382 & 1696 & 686 & 42439 \\
\hline & $7.5 \%$ & $6.5 \%$ & $1.0 \%$ & 6.865 & 6.838 & 0.027 & 2604 & 1961 & 643 & 23846 \\
\hline & $10.0 \%$ & $8.7 \%$ & $1.3 \%$ & 6.802 & 6.764 & 0.038 & 2829 & 2230 & 600 & 15901 \\
\hline & $15.0 \%$ & $13.1 \%$ & $1.9 \%$ & 6.673 & 6.614 & 0.059 & 3288 & 2774 & 514 & 8695 \\
\hline & $20.0 \%$ & $17.5 \%$ & $2.5 \%$ & 6.540 & 6.460 & 0.080 & 3758 & 3328 & 429 & 5343 \\
\hline & $25.0 \%$ & $21.9 \%$ & $3.1 \%$ & 6.403 & 6.301 & 0.101 & 4241 & 3895 & 346 & 3410 \\
\hline & $30.0 \%$ & $26.4 \%$ & $3.6 \%$ & 6.260 & 6.138 & 0.122 & 4739 & 4475 & 264 & 2156 \\
\hline
\end{tabular}

ICER=incremental cost-effectiveness ratio, NA=not applicable.

*The 10-year vascular disease risk was estimated from the expected number of first vascular events (fatal and nonfatal myocardial infarction or stroke) over the first 10 years divided by the total number of simulated people.

small and were not modelled. All cost estimates were updated to 2008 with the Dutch consumer price indices (http://statline.cbs.nl), and calculated in euros (table 1).

\section{Analysis}

We examined the effect of different levels of 10-year risk of vascular disease $(1 \%, 2.5 \%, 5 \%, 7.5 \%, 10 \%, 15 \%$, $20 \%, 25 \%$, and $30 \%$ ) separately for men and women of different ages. For the analysis, clinical courses of 100000 hypothetical persons for both strategies were evaluated and a time horizon of 10 years was used. Discounting was done at a rate of $4 \%$ for costs and $1.5 \%$ for health outcomes following Dutch guidelines. ${ }^{43}$ One way sensitivity analyses were done for statin pill costs, adverse effects, lower effectiveness of statins for people older than 65 years, ${ }^{7}$ non-adherence, disutility from taking a daily pill, varying baseline utility by age to account for declining quality of life over time, ${ }^{44}$ and discount rate. Our base case scenario considered men aged 55 years with a 10-year risk for vascular disease of $10 \%$. We also explored the impact of alternative time horizons (20-year and lifetime). For these analyses, we assumed that both groups (initial statin users and nonusers) adopted statin treatment after 10 years.

Parameter uncertainty was dealt with by probabilistic sensitivity analysis using Monte Carlo simulation with 1000 iterations for each evaluation. For each iteration, a value of each input variable was selected randomly from its distribution given in table 1 . Results from the probabilistic sensitivity analysis were presented as a scatter plot of incremental cost-effectiveness ratios and as a cost-effectiveness acceptability curve. The latter curve shows the probability that statin therapy is cost-effective for a range of cost-effectiveness thresholds. 
Table 3|Women: quality-adjusted life expectancy and costs of statins compared with no statins on cohorts of Dutch women at different ages over a 10 -year period

\begin{tabular}{|c|c|c|c|c|c|c|c|c|c|c|}
\hline \multirow[b]{2}{*}{$\begin{array}{c}\text { Age } \\
\text { (years) }\end{array}$} & \multicolumn{3}{|c|}{ 10-year vascular risk* } & \multicolumn{3}{|c|}{ QALYs } & \multicolumn{3}{|c|}{ Costs $(€)$} & \multirow[b]{2}{*}{$\begin{array}{c}\text { ICER } \\
(€ \text { per QALY) }\end{array}$} \\
\hline & No statins & Statins & $\begin{array}{l}\text { Absolute } \\
\text { risk } \\
\text { reduction }\end{array}$ & Statins & No statins & $\begin{array}{c}\text { Incremental } \\
\text { QALYs }\end{array}$ & Statins & No statins & $\begin{array}{c}\text { Incremental } \\
\text { costs }(€)\end{array}$ & \\
\hline \multicolumn{11}{|l|}{45} \\
\hline & $1.0 \%$ & $0.9 \%$ & $0.1 \%$ & 9.178 & 9.183 & -0.005 & 1225 & 271 & 954 & NA \\
\hline & $2.5 \%$ & $2.2 \%$ & $0.3 \%$ & 9.157 & 9.158 & -0.001 & 1507 & 600 & 907 & NA \\
\hline & $5.0 \%$ & $4.4 \%$ & $0.6 \%$ & 9.120 & 9.116 & 0.005 & 1982 & 1152 & 829 & 177029 \\
\hline & $7.5 \%$ & $6.6 \%$ & $0.9 \%$ & 9.084 & 9.073 & 0.011 & 2460 & 1709 & 752 & 71474 \\
\hline & $10.0 \%$ & $8.8 \%$ & $1.2 \%$ & 9.046 & 9.030 & 0.016 & 2943 & 2269 & 675 & 41275 \\
\hline \multicolumn{11}{|l|}{55} \\
\hline & $2.5 \%$ & $2.2 \%$ & $0.3 \%$ & 9.045 & 9.046 & -0.001 & 1488 & 582 & 906 & NA \\
\hline & $5.0 \%$ & $4.4 \%$ & $0.6 \%$ & 9.008 & 9.003 & 0.005 & 1891 & 1053 & 838 & 167080 \\
\hline & $7.5 \%$ & $6.5 \%$ & $1.0 \%$ & 8.971 & 8.960 & 0.011 & 2298 & 1527 & 770 & 70207 \\
\hline & $10.0 \%$ & $8.7 \%$ & $1.3 \%$ & 8.934 & 8.917 & 0.017 & 2708 & 2005 & 703 & 41544 \\
\hline & $15.0 \%$ & $13.1 \%$ & $1.9 \%$ & 8.857 & 8.829 & 0.029 & 3541 & 2972 & 569 & 19772 \\
\hline & $20.0 \%$ & $17.6 \%$ & $2.4 \%$ & 8.779 & 8.739 & 0.041 & 4392 & 3955 & 437 & 10758 \\
\hline & $25.0 \%$ & $22.0 \%$ & $3.0 \%$ & 8.699 & 8.646 & 0.052 & 5263 & 4957 & 306 & 5846 \\
\hline \multicolumn{11}{|l|}{65} \\
\hline & $5.0 \%$ & $4.4 \%$ & $0.6 \%$ & 8.719 & 8.711 & 0.008 & 1892 & 1061 & 831 & 99857 \\
\hline & $7.5 \%$ & $6.5 \%$ & $1.0 \%$ & 8.673 & 8.657 & 0.016 & 2236 & 1462 & 773 & 48837 \\
\hline & $10.0 \%$ & $8.7 \%$ & $1.3 \%$ & 8.626 & 8.603 & 0.023 & 2583 & 1867 & 716 & 30673 \\
\hline & $15.0 \%$ & $13.2 \%$ & $1.8 \%$ & 8.531 & 8.493 & 0.038 & 3287 & 2686 & 601 & 15703 \\
\hline & $20.0 \%$ & $17.6 \%$ & $2.4 \%$ & 8.434 & 8.380 & 0.053 & 4008 & 3520 & 488 & 9177 \\
\hline & $25.0 \%$ & $22.1 \%$ & $2.9 \%$ & 8.333 & 8.265 & 0.068 & 4746 & 4369 & 376 & 5531 \\
\hline \multicolumn{11}{|l|}{75} \\
\hline & $5.0 \%$ & $4.4 \%$ & $0.6 \%$ & 7.906 & 7.893 & 0.013 & 2080 & 1299 & 781 & 58110 \\
\hline & $7.5 \%$ & $6.6 \%$ & $0.9 \%$ & 7.846 & 7.823 & 0.023 & 2328 & 1591 & 737 & 31712 \\
\hline & $10.0 \%$ & $8.8 \%$ & $1.2 \%$ & 7.785 & 7.752 & 0.033 & 2578 & 1886 & 692 & 20981 \\
\hline & $15.0 \%$ & $13.2 \%$ & $1.8 \%$ & 7.661 & 7.608 & 0.052 & 2484 & 604 & 11513 & \\
\hline & $20.0 \%$ & $17.6 \%$ & $2.4 \%$ & 7.533 & 7.461 & 0.072 & 3611 & 3094 & 517 & 7190 \\
\hline & $25.0 \%$ & $22.1 \%$ & $2.9 \%$ & 7.401 & 7.310 & 0.091 & 4147 & 3717 & 430 & 4719 \\
\hline & $30.0 \%$ & $26.6 \%$ & $3.4 \%$ & 7.265 & 7.155 & 0.110 & 4700 & 4355 & 344 & 3122 \\
\hline
\end{tabular}

ICER=incremental cost-effectiveness ratio, NA=not applicable.

* The 10-year vascular disease risk was estimated from the expected number of first vascular events (fatal and nonfatal myocardial infarction or stroke) over the first 10 years divided by the total number of simulated people.

\section{RESULTS}

Table 2 and table 3 show the costs per QALY estimates for the use of statin treatment in primary prevention by vascular risk levels, age, and sex. Statin treatment in men aged 55 years with a 10 -year vascular risk of $10 \%$ resulted in a mean QALY gain (from 8.80 to 8.82 ) over 10 years. The statin treatment strategy was associated with additional mean costs of $€ 702$ per person ( $€ 1875$ for no treatment versus $€ 2577$ for statin treatment strategy). The cost difference was attributable to statin treatment costs (€932 per person), which were partly compensated for by fewer vascular events in the statin treatment strategy. Statin treatment for 10 years resulted in an incremental cost-effectiveness ratio of $€ 35000$ per QALY gained compared with no treatment.

Statin treatment in men aged 65 with a 10 -year vascular risk of $10 \%$ resulted in a larger QALY gain (from 8.15 to 8.18 ) over ten years. Statin treatment was associated with additional $€ 672$ costs per person, resulting in an incremental cost-effectiveness ratio of $€ 24600$ per QALY gained.

In general, the incremental cost-effectiveness ratios improved as risk for vascular disease increased. The incremental cost-effectiveness ratios slightly decreased with age after the level of vascular risk was specified. The predicted health benefits were somewhat lower in women, which resulted in slightly higher incremental cost-effectiveness ratios.

\section{Sensitivity analyses}

One way sensitivity analyses showed that the results of the model were most sensitive to assumptions on the costs of statin treatment, statin effectiveness, nonadherence, and disutility from taking a statin pill every day (table 4). Statin pill costs ( $€ 9$ a year in the base case) had an important effect on the incremental cost-effectiveness ratio. If costs of the statin pills were as high as $€ 100$ a year, the cost per QALY gained would increase from $€ 35000$ to almost $€ 55000$. If statins were 




$\overline{\text { Fig } 2}$ | Sensitivity analysis: cost-effectiveness results for different time horizons of the model.

less effective in elderly people, the incremental costeffectiveness ratio would also become less favourable. Improvement in adherence would enhance the costeffectiveness of statin treatment. If adherence levels as seen in the trials ("full" adherence scenario) were reached, the cost per QALY gained with statins would decrease to $€ 26000$. Assuming no disutility from taking a statin pill every day improved the incremental cost-effectiveness ratio substantially, the cost per QALY gained would decrease to $€ 26000$. The impact of the time horizon on the results was also subjected to sensitivity analysis. Extending the time horizon of the model to 20 years or lifetime decreased the costs per QALY relative to base case levels, particularly for people at younger ages (fig 2).

Figure 3 shows the results of the probabilistic sensitivity analysis for 55 year old men with a 10 -year vascular risk of $10 \%$. Hence, at a threshold of $€ 20000$ per QALY, the probability that statin treatment is costeffective is $16 \%$. There is a $97 \%$ chance that statin treatment is cost-effective at a threshold of $€ 80000 / \mathrm{QALY}$.

\section{DISCUSSION}

This study showed that the cost-effectiveness of statin treatment for primary prevention in daily practice ranged from $€ 5000$ to $€ 125000$ when the 10 -year vascular risk for middle aged men was varied from $25 \%$ to $5 \%$. Results were sensitive to the costs of statin treatment, statin effectiveness, non-adherence, disutility of taking medication daily, and the time horizon of the model.

In the past few decades, many studies have been published on the cost-effectiveness of statin treatment for primary prevention of vascular disease. ${ }^{13-18}$ Previous studies showed that the cost-effectiveness of statin treatment depends on the absolute level of vascular disease risk in the population treated and the age and sex of the population under consideration. Such studies introduced labelling of risk of vascular disease or

Table 4| One-way sensitivity analyses examining incremental cost-effectiveness ratio of 10 years statin treatment in men aged 55 years and 65 years with a 10 -year risk of vascular disease of $10 \%$

\begin{tabular}{|c|c|c|c|c|c|c|}
\hline \multirow[b]{2}{*}{ Assumption } & \multicolumn{3}{|c|}{55 year old men } & \multicolumn{3}{|c|}{65 year old men } \\
\hline & QALYs & Costs $(€)$ & ICER (€ per QALY) & QALYs & Costs $(€)$ & ICER (€ per QALY) \\
\hline Base-case scenario & 0.020 & 702 & 34995 & 0.027 & 672 & 24607 \\
\hline \multicolumn{7}{|l|}{ Statin pill costs (base case, $€ 9$ per year) } \\
\hline$€ 100$ & 0.020 & 1096 & 54595 & 0.027 & 1042 & 38151 \\
\hline$€ 300$ & 0.020 & 1958 & 97545 & 0.027 & 1852 & 67832 \\
\hline \multicolumn{7}{|c|}{ Risk for myopathy (base case, 12 per 100000 persons per year) } \\
\hline 20 & 0.020 & 702 & 35115 & 0.027 & 672 & 24665 \\
\hline 100 & 0.019 & 702 & 36320 & 0.027 & 671 & 25238 \\
\hline \multicolumn{7}{|c|}{ Statin effectiveness varies by age (base case, fixed effectiveness by age) } \\
\hline If less effective for people aged $>65$ years* & NA & NA & NA & 0.016 & 710 & 43914 \\
\hline \multicolumn{7}{|l|}{ Adherence (base case, real world adherence) } \\
\hline Full adherence & 0.032 & 831 & 25848 & 0.044 & 804 & 18315 \\
\hline \multicolumn{7}{|c|}{$\begin{array}{l}\text { Disutility from taking a pill every day, in days traded away assuming a 10- } \\
\text { year course of treatment (base case, } 5 \text { days) }\end{array}$} \\
\hline No disutility & 0.027 & 702 & 26394 & 0.033 & 672 & 20098 \\
\hline \multicolumn{7}{|l|}{ Baseline utility (base case, 1 for all ages) } \\
\hline If baseline utility decreases by age & 0.017 & 702 & 41071 & 0.023 & 672 & 28875 \\
\hline \multicolumn{7}{|c|}{ Discount rate (base case, costs $4 \%$, health outcomes $1.5 \%$ ) } \\
\hline $4 \%$ for both costs and health outcomes & 0.017 & 702 & 41764 & 0.023 & 672 & 29174 \\
\hline $3 \%$ for both costs and health outcomes & 0.018 & 732 & 40557 & 0.025 & 699 & 28375 \\
\hline
\end{tabular}





Fig 3 |Probabilistic sensitivity analysis and cost-effectiveness acceptability curve. Top: results of probabilistic sensitivity analysis for base case of 55 year old men (10-year vascular risk of $10 \%)$. Each dot represents 1 iteration of the model. $Y$ axis represents incremental costs of statins compared with no therapy. $X$ axis represents incremental QALYs with statins compared with no therapy. Diagonal lines represent a cost per QALY gained of $€ 20000$ and of $€ 80000$. Below: $Y$ axis represents probability that the cost per QALY gained is less than or equal to values on $X$ axis. ICER=incremental costeffectiveness ratio

mortality as "low", "medium" or "high". In view of the natural increase in vascular risk owing to age, it is difficult to label a certain level of risk as low, average, or high. For example, a 10-year vascular risk of $15 \%$ is a very high risk for men aged 45 years, whereas it is an average risk in people aged 65 years. We propose that a reference to absolute risk levels should always be made when labelling risks as low, medium, or high.

\section{Strengths of the study}

Although the prices of statins have fallen, our model produced cost-effectiveness results similar to those of earlier analyses. This finding may seem counterintuitive, because the price of statins does affect the costeffectiveness results. However, other factors are involved when targeting statins to primary prevention populations. We took into account the effect of incomplete adherence to statin therapy, attributed a disutility to the act of taking medication daily, and shortened the time frame of the model to 10 years. These factors offset the cost saving effect of generic statin prices. None of the previous studies accounted for all these factors simultaneously. Consequently, our study provides a more complete overview of the cost-effectiveness of the use of statins for the primary prevention of vascular disease in daily practice. Clinicians who wish to use these results need to assess the risk of vascular disease in all middle aged and older adults and in younger adults with additional risk factors, using one of the validated risk prediction models (SCORE or Framingham). Depending on a country's willingness to pay for a QALY, clinicians should prescribe statins to all people in risk groups with relatively attractive levels of cost-effectiveness, irrespective of the level of any of the individual risk factors.

\section{Limitations}

Our model has some limitations. First, the base case analysis was run for 10 years instead of the complete lifetime. The sensitivity analysis showed that if the modelling was undertaken over a person's lifetime this would lead to more favourable cost-effectiveness results, especially for younger people. However, we believe that if treatment is started in relatively healthy young individuals it will be very difficult to continue this treatment over the person's lifetime. Moreover, we judged a 10-year period to be long enough to capture the major health and economic consequences of taking statins in the primary prevention of vascular events. Second, our results are based on a model that did not incorporate the details of a patient's course after a first, nonfatal vascular event. Instead, we assigned them an increased risk for death, increased costs, and a disutility associated with their health state. This simplified approach was adopted because modelling secondary events did not have a large influence on our results, and it prevented the model from becoming too complex. Third, we assumed that statin treatment confers a continuous benefit beyond the trial follow-up period. This assumption is common in cost-effectiveness models and may be reasonable since treatment is still ongoing at the end of trial follow-up. Fourth, we used Dutch estimates for drug costs. The low statin pill costs in the Netherlands are not achievable in most countries in the foreseeable future. Higher costs of statin pills would strengthen our conclusion that statins have a limited role in primary prevention in view of the current low adherence rates. Fifth, we conducted our economic analysis from the healthcare payer's perspective (implying that only direct medical costs are included). If indirect costs representing the loss of productivity were included, statin treatment would be expected to become more cost-effective. ${ }^{45}$

\section{Implications}

In conclusion, this study showed that even at current low costs for generic statin pills, statin treatment seemed not to be cost-effective for low risk primary prevention populations (10-year vascular disease risk $<5 \%)$ in the Netherlands, when non-adherence was taken into account. Adherence to statin therapy needs to be improved to enhance the cost-effectiveness of the use of statins for primary prevention. 


\section{WHAT IS ALREADY KNOWN ON THIS TOPIC?}

Statins reduce the risk of major cardiovascular and cerebrovascular events in people without established cardiovascular disease.

Overall risk of vascular disease events, rather than single risk factors, determines the absolute benefits of statin therapy.

Adherence to statin treatment in daily practice is suboptimal and may impair costeffectiveness.

\section{WHAT THIS STUDY ADDS?}

Statin treatment seemed not to be cost-effective for low risk primary prevention populations, despite low costs of generic drugs

Adherence to statins needs to be improved to enhance cost-effectiveness.

Contributors: JPG developed the cost-effectiveness model, analysed the data, and wrote the manuscript. She is guarantor. GAdW, AA, and FLV contributed to model development and data collection, and critically revised the manuscript.

Funding: This study was supported by an unconditional grant from the Netherlands Organisation for Health Research and Development (ZonMW, project number 6120.0019). The funding source had no involvement in study design; in the collection, analysis, and interpretation of data; in the writing of the report; and in the decision to submit an article for publication

Competing interests: All authors have completed the Unified Competing Interest form at www.icmje.org/coi_disclosure.pdf (available on request from the corresponding author) and declare that: the submitted work was supported only by ZonMW; JPG, GAdW, and AA have no relationships with companies that might have an interest in the submitted work in the previous three years; the department of FLV has received research grants from Merck, the Netherlands Organisation for Health research and Development and from the Catharijne foundation Utrecht and speaker fees from Merck and AstraZeneca; none of the authors has non-financial interests that may be relevant to the submitted work.

Ethical approval: Not required.

Data sharing: No additional data available.

1 Vaartjes I, Reitsma JB, de Bruin A, Berger-van Sijl M, Bos MJ, Breteler MM,et al. Nationwide incidence of first stroke and TIA in the Netherlands. Eur / Neurol 2008:15:1315-23.

2 American Heart Association. Heart disease and stroke statistics2008 update. 2008. www.americanheart.org/downloadable/heart/ 1200082005246HS_Stats\%202008.final.pdf.

3 Cholesterol Treatment Trialists' (CT) Collaborators. Efficacy and safety of cholesterol-lowering treatment: prospective meta-analysis of data from 90,056 participants in 14 randomised trials of statins. Lancet 2005;366:1267-78.

4 LaRosa JC, He J, Vupputuri S. Effect of statins on risk of coronary disease: a meta-analysis of randomized controlled trials. JAMA 1999;282:2340-6.

5 Mills EJ, Rachlis B, Wu P, Devereaux PJ, Arora P, Perri D. Primany prevention of cardiovascular mortality and events with statin treatments: a network meta-analysis involving more than 65,000 patients. I Am Coll Cardiol 2008;52:1769-81.

6 Thavendiranathan P, Bagai A, Brookhart MA, Choudhry NK. Primary prevention of cardiovascular diseases with statin therapy: a metaanalysis of randomized controlled trials. Arch Intern Med 2006;166:2307-13.

7 Brugts JJ, Yetgin T, Hoeks SE, Gotto AM, Shepherd J, Westendorp RG, et al. The benefits of statins in people without established cardiovascular disease but with cardiovascular risk factors: metaanalysis of randomised controlled trials. BMJ 2009:338:b2376.

8 Ray KK, Seshasai SR, Erqou S, Sever P, Jukema JW, Ford I, et al. Statins and all-cause mortality in high-risk primary prevention: a meta-analysis of 11 randomized controlled trials involving 65,229 participants. Arch Intern Med 2010;170:1024-31.

9 Bates TR, Connaughton VM, Watts GF. Non-adherence to statin therapy: a major challenge for preventive cardiology. Expert Opin Pharmacother 2009;10:2973-85.

10 Perreault S, Ellia L, Dragomir A, Cote R, Blais L, Berard A,et al. Effect of statin adherence on cerebrovascular disease in primary prevention. Am / Med 2009:122:647-55.

11 Christie B. Guidelines on treating risk factors turn healthy people into patients, doctors say. BMJ 2006;333:988.
12 Greving JP, Buskens E, Koffijberg H, Algra A. Cost-effectiveness of aspirin treatment in the primary prevention of cardiovascular disease events in subgroups based on age, gender, and varying cardiovascular risk. Circulation 2008;117:2875-83.

13 Huse DM, Russell MW, Miller JD, Kraemer DF, D’Agostino RB, Ellison RC,et al. Cost-effectiveness of statins. Am J Cardiol 1998;82:1357-63.

14 Pickin DM, McCabe CJ, Ramsay LE, Payne N, Haq IU, Yeo WW,et al. Cost effectiveness of HMG-CoA reductase inhibitor (statin) treatment related to the risk of coronary heart disease and cost of drug treatment. Heart 1999;82:325-32.

15 Prosser LA, Stinnett AA, Goldman PA, Williams LW, Hunink MG, Goldman L,et al. Cost-effectiveness of cholesterol-lowering therapies according to selected patient characteristics. Ann Intern Med 2000;132:769-79.

16 Johannesson M. At what coronary risk level is it cost-effective to initiate cholesterol lowering drug treatment in primary prevention? Eur Heart J 2001;22:919-25.

17 Pignone M, Earnshaw S, Tice JA, Pletcher MJ. Aspirin, statins, or both drugs for the primary prevention of coronary heart disease events in men: a cost-utility analysis. Ann Intern Med 2006;144:326-36.

18 Ward S, Lloyd IM, Pandor A, Holmes M, Ara R, Ryan A, et al. A systematic review and economic evaluation of statins for the prevention of coronary events. Health Technol Assess 2007;11:1-iv.

19 Ridker PM, Danielson E, Fonseca FA, Genest J, Gotto AM Jr, Kastelein JJ,et al. Rosuvastatin to prevent vascular events in men and women with elevated C-reactive protein. $N$ Engl J Med 2008;359:2195-207.

20 Sonnenberg FA, Beck JR. Markov models in medical decision making: a practical guide. Med Decis Making 1993;13:322-38.

21 Koek H, de Bruin A, Gast A, Gevers E, Kardaun J, Reitsma J,et al. Incidence of first acute myocardial infarction in the Netherlands. Neth J Med 2007;65:434-41.

22 Jager-Geurts MH, Peters RJG, van Dis SJ, Bots ML. Cardiovascular diseases in The Netherlands 2006. Figures on risk factors, morbidity and mortality. Netherlands Heart Foundation, 2006.

23 Koek H, de Bruin A, Gast F, Gevers E, Kardaun JW, Reitsma JB, et al. Short- and long-term prognosis after acute myocardial infarction in men versus women. Am J Cardiol 2006;98:993-9.

24 Law M, Rudnicka AR. Statin safety: a systematic review. Am J Cardiol 2006;97:52-60C

25 Statistics Netherlands. Lifetables: Dutch population by age and sex, 1996-2000. Statistics Netherlands, 2002.

26 Bronnum-Hansen $\mathrm{H}$, Jorgensen T, Davidsen M Madsen M, Osler M, Gerdes LU,et al. Survival and cause of death after myocardial infarction: the Danish MONICA study. J Clin Epidemiol 2001;54:1244-50.

27 Lampe FC, Whincup PH, Wannamethee SG, Shaper AG, Walker M, Ebrahim S. The natural history of prevalent ischaemic heart disease in middle-aged men. Eur Heart J 2000;21:1052-62.

28 Bronnum-Hansen H, Davidsen M, Thorvaldsen P. Long-term survival and causes of death after stroke. Stroke 2001;32:2131-6.

29 Dennis MS, Burn JP, Sandercock PA, Bamford JM, Wade DT, Warlow CP. Long-term survival after first-ever stroke: the Oxfordshire Community Stroke Project. Stroke 1993;24:796-800.

30 Wolfe CD. The impact of stroke. Br Med Bull 2000;56:275-86.

31 Helin-Salmivaara A, Lavikainen P, Korhonen MJ, Halava H, Junnila SY, Kettunen R,et al. Long-term persistence with statin therapy: a nationwide register study in Finland. Clin Ther 2008;30:2228-40.

32 Avorn J, Monette J, Lacour A, Bohn RL, Monane M, Mogun H, et al. Persistence of use of lipid-lowering medications: a cross-national study. JAMA 1998;279:1458-62.

33 Hiatt JG, Shamsie SG, Schectman G. Discontinuation rates of cholesterol-lowering medications: implications for primary care. Am Manag Care 1999;5:437-44.

34 Tsevat J, Goldman L, Soukup JR, Lamas GA, Connors KF, Chapin CC, et al. Stability of time-tradeoff utilities in survivors of myocardial infarction. Med Decis Making 1993;13:161-5.

35 Post PN, Stiggelbout AM, Wakker PP. The utility of health states after stroke: a systematic review of the literature. Stroke 2001;32:1425-9.

36 Augustovski FA, Cantor SB, Thach CT, Spann SJ. Aspirin for primary prevention of cardiovascular events. J Gen Intern Med 1998;13:824-35.

37 Naglie IG, Detsky AS. Treatment of chronic nonvalvular atrial fibrillation in the elderly: a decision analysis. Med Decis Making 1992;12:239-49.

38 Dutch Health Care Insurance Board. Drug costs. 2009. www. medicijnkosten.nl.

39 Dutch Healthcare Authority. Rates for various professionals and various laboratory tests. 2009. www.nza.nl.

40 De Boer MJ, van Hout BA, Liem AL, Suryapranata H, Hoorntje JC, Zijlstra F. A cost-effective analysis of primary coronary angioplasty versus thrombolysis for acute myocardial infarction. Am J Cardiol 1995;76:830-3. 
41 Johannesson M, Jonsson B, Kjekshus J, Olsson AG, Pedersen TR, Wedel $\mathrm{H}$. Cost effectiveness of simvastatin treatment to lower cholesterol levels in patients with coronary heart disease. Scandinavian Simvastatin Survival Study Group. N Engl J Med 1997;336:332-6.

42 Buskens E, Nederkoorn PJ, Buijs-van der Woude T, Mali WP, Kappelle L), Eikelboom BC,et al. Imaging of carotid arteries in symptomatic patients: cost-effectiveness of diagnostic strategies. Radiology 2004;233:101-12.

43 Oostenbrink JB, Bouwmans CAM, Koopmanschap MA, Rutten FFH. Guideline for costing research. Methods and standardized prices for economic evaluations in health care. Health Care Insurance Board (The Netherlands), 2004.

44 Stolk E, Krabbe P, Busschbach J. Using the Internet to collect EQ-5D norm scores: a valid alternative? Proceedings of the Plenary Meeting of the EuroQol Group 2007;153:65.

45 Grover SA, Ho V, Lavoie F, Coupal L, Zowall H, Pilote L. The importance of indirect costs in primary cardiovascular disease prevention: can we save lives and money with statins? Arch Intern Med 2003;163:333-9.

Accepted: 29 December 2010 